\title{
NEIBA
}

\section{Raça, racismo e operações de paz: uma análise crítica da}

\section{MINUSTAH}

\section{Lucas Guerra}

Vínculo Institucional: Instituto de Relações Internacionais - Pontifícia Universidade Católica do Rio de Janeiro (IRI/PUC-Rio)

\section{Resumo:}

No presente trabalho, argumentamos que a raça e o racismo são elementos estruturantes da política mundial moderna, e que essa dimensão racializada pode ser observada nas operações de paz da ONU contemporâneas. Nesse sentido, partindo de uma metodologia essencialmente qualitativa, abordamos as formas com que as categorizações hierárquicas inicialmente baseadas em distinções biológicas entre brancos e não-brancos foram historicamente ressignificadas, assumindo a forma de padrões civilizatórios e de discursos de modernização. Argumentamos ainda que esses discursos racializados constituem a base de conceitos centrais das narrativas ortodoxas sobre resolução de conflitos e processos de pacificação, como a paz liberal, os "Estados falidos" e o peacebuilding e statebuilding. Finalmente, apresentamos um estudo de caso da Missão das Nações Unidas para a Estabilização do Haiti (MINUSTAH) a partir de um enfoque em aspectos de raça e racismo, argumentando que lógicas racializadas presentes na Missão levam à sua instrumentalização para a despossessão do povo negro haitiano de alguns de seus direitos fundamentais, dentre eles o da autodeterminação.

Palavras-chaves:

Racismo; operações de paz; Estados falidos; statebuilding; peacebuilding.

\section{Abstract:}

In the present work, we argue that race and racism are structuring elements of modern world politics, and that this racialized dimension can be observed in contemporary UN peace operations. In this sense, starting from an essentially qualitative methodology, we approach the ways in which the hierarchical categorizations initially based on biological distinctions between whites and nonwhites have been historically re-signified, taking the form of civilization standards and discourses of modernization. We 


\section{NEIBA}

argue further that these racialized discourses form the basis of central concepts of orthodox narratives on conflict resolution and pacification processes, such as liberal peace, failed states, and peacebuilding and statebuilding. Finally, we present a case study of the United Nations Mission for the Stabilization of Haiti (MINUSTAH) based on a focus on aspects of race and racism, arguing that the racialized logic present in the mission leads to its instrumentalization for the dispossession of the Haitian black people of some of its fundamental rights, among them that of selfdetermination.

Keywords:

Failed States; statebuilding; peacebuilding. 


\section{NEİBA}

\section{Introdução}

O Haiti é o país com a maior porcentagem de população negrana América Latina e no Caribe, e também o mais pobre do hemisfério ocidental (BANCO MUNDIAL, 2018). De acordo com o FragileStates Index2018, o Haiti é também o único país fora da África e do Oriente Médio considerado em "alerta vermelho" de risco de colapso estatal. Nosso argumento nesse artigo é que esses não são fatos isolados; pelo contrário, estão intrinsecamente relacionados.

Argumentamos, portanto, que o tratamento da comunidade internacional ao Haiti recentemente expressado pela presença da Missão das Nações Unidas para a Estabilização do Haiti (MINUSTAH) no país entre 2004 e 2017 - está permeado por elementos do racismo, entendido como parte constituinte das relações internacionais na modernidade. Assim, pretendemos arguir que o racismo historicamente presente nas abordagens da comunidade internacional ao Haiti, culminantes na MINUSTAH, decorre na despossessão do povo haitiano sobre seus direitos fundamentais, dentre eles o de controle sobre os rumos políticos e econômicos do próprio país.

Para a sustentação do argumento, optamos por uma metodologia essencialmente qualitativa, baseada na consulta de fontes majoritariamente secundárias concernentes às temáticas abordadas no trabalho e culminando em um breve estudo de caso da Missão das Nações Unidas para a Estabilização do Haiti (MINUSTAH). Ademais, organizamos a distribuição do texto em três seções além desta, às quais se seguem algumas das considerações finais obtidas como resultado da pesquisa aqui exposta.

Na primeira seção, apresentamos nossas aproximações teóricas e conceituais instrumentalizadas ao longo da argumentação, com especial ênfase em nosso entendimento de raça, racismo e sua relação com as Relações Internacionais. $\mathrm{Na}$ segunda, utilizamos as ferramentas analíticas apresentadas na seção anterior para abordar as operações de paz das Nações Unidas, especialmente as de peacebuilding e seus processos de statebuilding, bem como os elementos da narrativa internacional que legitimam essas práticas. Finalmente, na terceira seção apresentamos uma reflexão acerca dos elementos racistas presentes na MINUSTAH, situando-a como expressão de um longo histórico de ferramentas da comunidade internacional para a "estabilização" da "República Negra" e argumentando que sua atuação decorre na despossessão do povo haitiano do direito à vida, à dignidade e à autodeterminação.

\section{Raça, racismo e Relações Internacionais}

$\mathrm{Na}$ perspectiva analítica adotada nesse artigo, partimos da necessidade de contribuir com abordagens às Relações Internacionais que lancem luz a um dos silenciamentos centrais presentes nas abordagens teóricas dominantes na disciplina ${ }^{1}$ : a centralidade do racismo como elemento estrutural constituinte dos entendimentos fundamentais de nosso campo de estudos e da política internacional de maneira geral. Por esse motivo, temas centrais concernentes aos estudos de operações de paz - a questão do uso da força, disseminação de normas, adequação institucional, composição dos atores, legitimidade, eficiência etc. - são tangenciados a partir de um enfoque que prioriza a sua dimensão racializada na narrativa internacional. Antes disso, porém, é necessário um estabelecimento mais preciso do que entendemos por raça e racismo, e de que maneira isso se relaciona com as Relações Internacionais.

Primeiramente, nossa concepção de raça não é determinada de acordo com fatores biológicos, mas sim sociais e políticos (MILLS, 1997, p. 126). Seguindo o

\footnotetext{
${ }^{1}$ Seguindo os apontamentos de Steve Smith (2000), entendemos o mainstream teórico das RI como constituído pelas abordagens neorrealistas, neoliberal institucionalistas e construtivistas de via média, o campo "racionalista" da disciplina. Não é nosso objetivo nesse espaço, contudo, tecer maiores considerações a respeito desse tema.
} 


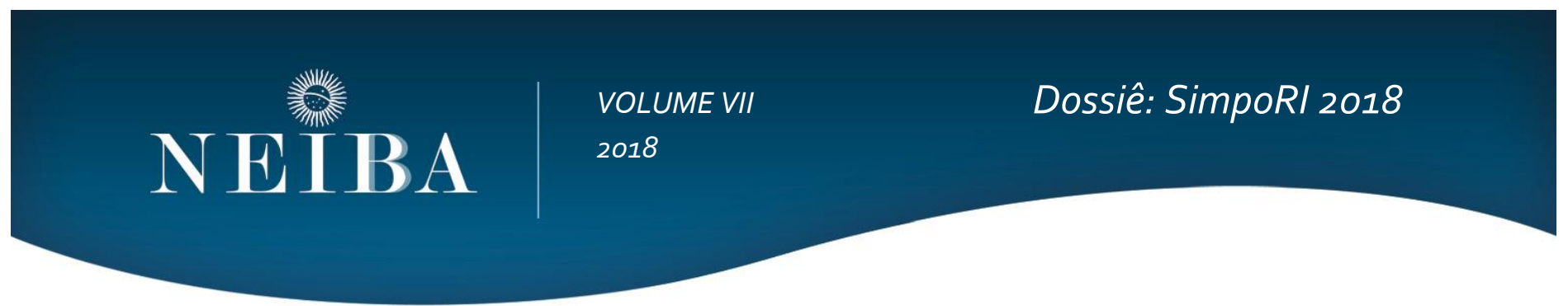

exemplo de Stuart Hall (2017, p. 45-50), entendemos a raça principalmente como um discurso que dá significado social às diferenças físicas de cor entre os seres humanos. Isto é, os fatores ditos "biológicos" - a diferença de cor inscrita na pele dos sujeitos - não possuem por si só nenhuma fundamentação para a categorização e atribuição de características subjetivas a grupos humanos de maneira "natural"; a utilização dessas diferenças para a categorização hierárquica da humanidade é resultado de práticas discursivas e regimes de representação socialmente construídos. Outro ponto importante da análise de Hall (2017, p. 45-46) que retomaremos mais tarde é que a raça é vista como um "significante escorregadio" (slidingsignifier), isto é, como um modo de significação da diferença moldável de acordo com as circunstâncias contextuais, geralmente se distanciando de formas de hierarquização estritamente biológicas para se sustentar em elementos culturais.

Assim, como reforça Achille Mbembe (2017, p. 11-17), a utilização do conceito de "raça", originalmente utilizado apenas para a classificação de animais, como categoria aplicada à definição de seres humanos foi um marco fundamental do dualismo inaugural da organização hierárquica do mundo moderno. Com base em diferenças de cor, os seres humanos foram então classificados entre superiores e civilizados - os brancos europeus - e inferiores e bestializados - os negros, ameríndios, "amarelos", enfim, todos os povos não-brancos e não-europeus existentes ao redor do globo. Essa forma de representação discursiva foi instrumentalizada para a legitimação do colonialismo e do imperialismo como "missões civilizatórias", parte do "fardo do homem branco" de levar a civilização para o mundo, sedimentando assim as bases das relações internacionais entre "centro" e "periferia" inauguradas com a modernidade (MBEMBE, 2017, p. 17).

Nesse sentido, Charles Mills (1997, p. 13-20) afirma que o colonialismo foi o marco inaugural do que chama de "Contrato Racial", entendido como processo de desconsideração da condição humana e das formas de organização política dos povos não-brancos e disseminação, pelos brancos europeus, de modelos de Estado e configurações de ordem internacional favoráveis à manutenção dos privilégios de uma supremacia branca global. Tal processo se daria inicialmente pela legitimação do Estado-Nação no mundo colonial, cristalizando códigos jurídicos e morais favoráveis à dominação de elites brancas em seu interior (MILLS, 1997, p. 20). Assim, se consolidaria a supremacia branca em escala efetivamente global, com o direito internacional exercendo um papel central nesse processo $^{2}$ (ibidem). Assim, Mills (1997, p. 27) afirma que o mundo moderno foi fundado como uma comunidade política racial, sustentada pela dominação global dos brancos europeus.

Nesse ponto, a análise de Mills converge com a de teóricos decoloniais como Aníbal Quijano (2005, p. 117-118) e Walter Mignolo (2003, p. 53-54) no apontamento da raça e do racismo como categorias centrais na composição do Estado-Nação moderno e da própria divisão internacional do trabalho no interior de uma economia mundial capitalista. Tanto Mills (1997, p. 32-35) e os teóricos decoloniais quanto AchilleMbembe (2017, p. 20) convergem ao apontar que a superexploração do trabalho e mesmo a escravização de massas de corpos negros foram processos essenciais para o desenvolvimento econômico e tecnológico do que hoje compõe o centro (branco) do sistema interestatal capitalista. Em texto posterior, Mills (2015, p. 204) afirma que o estabelecimento dessas formas de categorização e relações de poder entre elites dominantes brancas e massas marginalizadas e superexploradas nãobrancas só foi possível mediante a existência de forças e processos globais inaugurados com as relações coloniais (MILLS, 2015, p. 204).

\footnotetext{
2 Para mais sobre as relações entre racismo, eurocentrismo e direito internacional, recomenda-se a leitura de Aalberts (2014).
} 


\section{NEİBA}

Analisando esse tipo de relação, W.E.B. Du Bois $(1925)^{3}$ foi pioneiro ao identificar a existência de uma "linha de cor" global como elemento estruturante das relações internacionais. Mais especificamente, Du Bois analisou a Primeira Guerra Mundial como ponto culminante do racismo que desde o início das práticas colonialistas e imperialistas permeia os movimentos da política internacional. É nesse ponto que a relação intrínseca entre raça, racismo e Relações Internacionais começa a ficar mais evidente. De fato, o artigo de Du Bois foi publicado na Foreign Affairs, importante revista da disciplina de RI fundada em 1922 como sucessora do Journal of International Relations, que por sua vez era sucessor do Journal of Racial Development(1911-1919); isto é, a questão racial estava presente mesmo nas discussões teóricas sobre a política mundialantecessoras ao surgimento das Relações Internacionais como disciplina acadêmica (SARAIVA, 2018)4.

Compartilhamos aqui da perspectiva de Alexander Anievas, NiviManchanda e Robbie Shilliam (2015, p. 9, tradução nossa, grifos nossos) de que:

[...] as RI podem ocupar uma posição estrategicamente distinta na academia, através da qual facilitariam o exame das conexões entre a raça como um princípio estruturante e os processos transnacionais de acumulação, despossessão, violência e luta que emergem a partir dela. Por exemplo, nós sugeriríamos que não somente a emergência do Estado-Nação e da modernidade capitalista como um projeto de maneira geral é indissociavelmente conectada a lógicas raciais, mas que a permanência dessas lógicas é evidente nas intervenções

\footnotetext{
3 Paginação não disponível na versão consultada.

${ }^{4}$ Paginação não disponível na versão consultada.
}

humanitárias liberais, construção de nações e formas modernas de escravidão e tráfico. Portanto, em vez de falar de um mundo pósracial em teoria ou na prática, nós preferimos nos reengajar estrategicamente com o argumento feito por Du Bois de que o problema do século vinte e um também é o problema da linha de cor, embora em outras geografias físicas e constelações sociais. ${ }^{5}$

Assim, ainda seguindo as indicações de Anievas, Manchanda e Shilliam (2015, p. 7), entendemos que uma episteme focada no papel da raça e do racismo na política mundial se apresenta como importante e produtiva agenda de pesquisa em Relações Internacionais. De acordo com os autores, essa proposta epistêmica estaria radicada em torno da linha de cor como aspecto central da estruturação e contestação histórica e contemporânea da ordem mundial; da necessidade e potencialidade de descentrar os "lugares de análise" (sociais, geográficos, intelectuais) dominantes nas teorias do mainstream da disciplina e no reconhecimento da intersecção do racismo com outras estruturas globais de opressão, como o capitalismo e o patriarcado (ibidem).

Em linha com as considerações de Branwen Jones (2015, p. 63), consideramos o estudo das operações de paz contemporâneas como uma área profícua para a

\footnotetext{
5 "[...]IR could occupy a strategically distinct position in academia through which to facilitate examination of the link between race as a structuring principle and the transnational processes of accumulation, dispossession, violence and struggle that emerge in its wake. For example, we would suggest that not only is the emergence of the nation-state, and capitalist modernity as a project more generally, inextricably linked to racial logics, the very persistence of these logics is evident in contemporary liberal humanitarian intervention, nation-building and modern forms of slavery and trafficking. Thus, rather than talk of a post-racial world of theory or practice, we prefer to strategically reengage with the argument made by Du Bois that the problem of the twenty-first century is equally the problem of the colour line, albeit in shifting social constellations and physical geographies".
} 


\section{NEIBA}

elaboração dessa proposta epistêmica nas Relações Internacionais. Antes de avançar nessa direção, contudo, retomamos alguns aspectos da análise de Stuart Hall (2017, p. 46) da "raça" como "significante escorregadio" (slidingsignifier) para melhor compreender a sua incidência sobre as narrativas e práticas da política internacional contemporânea.

Nesse sentido, Hall (2017, p. 54) afirma que a primeira forma que o discurso da diferença racial tomou, no momento do "encontro colonial" no qual prevaleciam as visões religiosas de mundo, foi o de questionamento acerca da "humanidade" ou não dos povos ameríndios se comparados a suas contrapartes europeias. No decorrer dos séculos, com a transição da autoridade sobre o conhecimento da Igreja para a "Ciência", a diferença racial foi ressignificada de maneira pretensamente científica, como cerne da categorização da humanidade em diferentes graus e etapas de "civilização", tendo a Europa como referência superior e as "sociedades tribais" africanas como a alteridade por excelência (HALL, 2017, p. 54-55).

Como lembra Tanja Aalberts (2014, p. 779781), esses discursos de darwinismo social e racismo científico serviram de legitimação para as investidas imperialistas das potências europeias como "missões civilizatórias", supostamente para o bem das sociedades locais dos países conquistados. AchilleMbembe (2017, p. 17) acrescenta que esse processo estabeleceu discursivamente uma narrativa de distância temporal intransponíveis entre europeus e não-europeus, brancos e não-brancos, com os primeiros em uma perpétua condição de avanço e superioridade com relação aos últimos.

É em sentido semelhante que se insere aquela que Stuart Hall (2017, p. 69-70) aponta como a ressignificação mais recente da categoria de raça como "significante escorregadio" nas representações discursivas contemporâneas. Na perspectiva do autor, compartilhada por Charles Mills (2015, p. 206), uma vez que o racismo "científico" baseado em argumentos biológicos se tornou insustentável, a raça e o racismo foram ressignificados na forma de diferenças culturais. Assim, emergiram a partir de meados do século $X X$ discursos atribuindo determinadas características culturais (proatividade/preguiça; cordialidade/agressividade; ascese/devassidão; idoneidade/corrupção; responsabilidade/irresponsabilidade; maturidade/infantilidade; racionalidade/irracionalidade etc.) como se fossem naturais de grupos raciais específicos, sempre com as características positivas atribuídas aos brancos e as negativas aos não-brancos (AALBERTS, 2014, p. 786).

Finalmente, Arturo Escobar (2007, p. 26-28) e Sankaran Krishna (2009, p. 9-13) argumentam que uma das formas recentes assumida por esse tipo de discurso e representação são as teorias da modernização e suas propostas de "desenvolvimento" para os países póscoloniais. Nas palavras de Escobar (2007, p. 28, tradução nossa):

[Para] a corrente principal da bibliografia sobre o desenvolvimento, [...] existe uma verdadeira subjetividade subdesenvolvida dotada de traços como a impotência, a passividade, a pobreza e a ignorância, comumente pela gente escura e carente de protagonismo como se estivesse à espera de uma mão ocidental (branca), e não poucas vezes faminta, analfabeta, necessitada, oprimida por sua própria obstinação, carente de iniciativas e de tradições. Essa imagem também universaliza e homogeneíza as culturas do Terceiro Mundo de forma ahistórica. $^{6}$

\footnotetext{
6 "[...] la corriente principal de la bibliografía sobre el desarrollo, para la cual existe una verdadera subjetividad subdesarrollada dotada con rasgos como la
} 


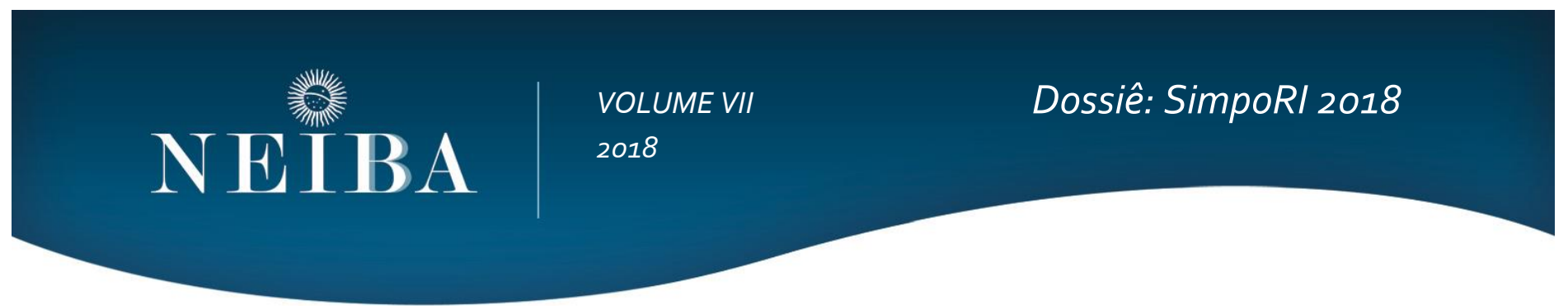

De maneira sucinta, é parte das propostas das teorias da modernização o apontamento dos modelos de governança política e econômica ocidentais/europeus como os únicos possíveis para se alcançar o desenvolvimento (KRISHNA, 2009, p. 14). Seguindo os apontamentos de Branwen Jones (2015, p. 72) e BaeteJahn (2007, p. 212), esse tipo de forma racializada e hierarquizada de representação das desigualdades e diferenças entre os países do Norte e do Sul Global é incorporado pelas perspectivas da paz liberal e pelos processos de statebuilding implementados pelas operações de paz das Nações Unidas contemporâneas. Dito isso, argumentamos que essas operações podem ser analisadas como manifestações das lógicas racistas que permeiam e estruturam as relações de poder internacionais.

\section{A dimensão racializada das operações de paz das Nações Unidas}

As operações de paz da Organização das Nações Unidas (ONU) não possuem um modelo homogêneo definido; de fato, ao longo de seus desdobramentos históricos, foram assumindo distintas configurações e assumindo diferentes tipos de tarefas, de acordo com contextos específicos no cenário internacional (GUERRA; BLANCO, 2018, p. 7-8)7. Aqui, destacamos que originalmente, essas operações eram regidas pelo que Alex Bellamy, Paul Williams e Stuart Griffin (2010, p. 173) chamam de a "Santíssima Trindade" das operações de paz: os princípios do consentimento entre as partes, não-

impotencia, la pasividad, la pobreza y la ignorancia, por lo común de gente oscura y carente de protagonismo como si se estuviera a la espera de una mano occidental (blanca), y no pocas veces hambrienta, analfabeta, necesitada, oprimida por su propia obstinación, carente de iniciativa y de tradiciones. Esta imagen también universaliza y homogeneiza las culturas del Tercer Mundo en una forma ahistórica".

7 Uma avaliação mais detalhada dos distintos modelos de operações de paz, seus princípios normativos e os contextos políticos em que se desenvolveram pode ser encontrada, por exemplo, em (KENKEL, 2013) ou (GUERRA; BLANCO, 2018). interferência em assuntos domésticos e proibição do uso da força para fins além da legítima defesa.

Não obstante, com as mudanças no caráter dos conflitos internacionais - passando a ser cada vez mais intraestatais - e um consenso geral presente na comunidade internacional no contexto pós-Guerra Fria acerca dos princípios liberais da democracia representativa e da economia de mercado como modelos de governança política e econômica universalmente desejáveis, houve uma inflexão no modo de atuação dessas operações (GUERRA; BLANCO, 2018, p. 9-10). Assim, o modelo de pacificação dominante passou a ser o de peacebuilding, que de acordo com a definição das próprias Nações Unidas (1992; 2008), tem por objetivo construir uma "paz sustentável"através do adereçamento das chamadas"causas estruturais" dos conflitos: a inexistência ou ineficácia dos mecanismos de governança política, social e econômica nas sociedades em situação de violência generalizada.

Sendo assim, as operações de peacebuilding passam a ter a responsabilidade de restituir capacidades de governança básica em países devastados por conflitos, incluindo em suas obrigações tarefas como o desarmamento, desmobilização e reintegração de combatentes (DDR), treinamento de forças policiais e militares, organização e monitoramento de eleições, retomada de territórios sob comando de grupos rebeldes, reconstrução infraestrutural, provisão de alimentos e assistência sanitária, capacitação institucional e administrativa dos Três Poderes da república e mesmo a redação de novas Constituições (BLANCO, 2014, p. 299; PARIS, 2004, p. 18). Para tanto, as operações de peacebuilding contemporâneas rompem com a "Santíssima Trindade" das operações de paz tradicionais, passando a incidir diretamente sobre assuntos domésticos dos Estados e a utilizar a força para a garantia da lei e da ordem (BELLAMY; WILLIAMS; GRIFFIN, 2010, p. 29-30). 


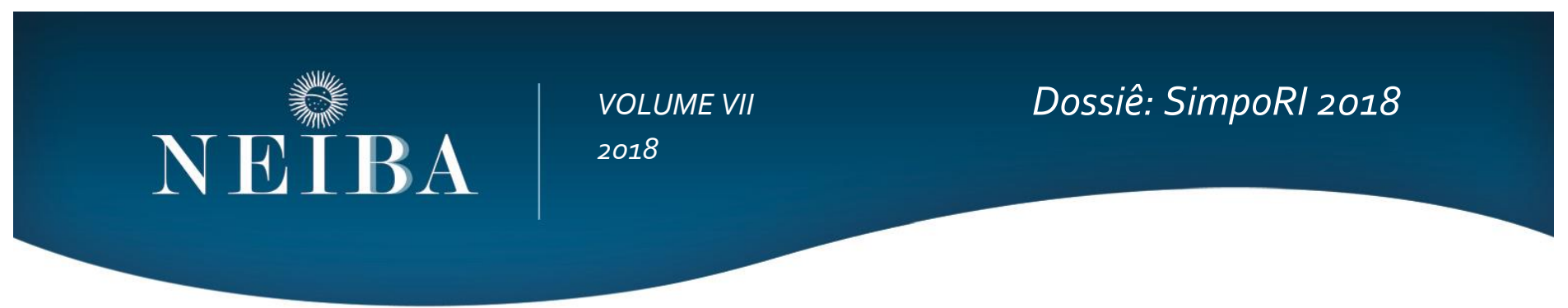

Outra importante característica das operações de peacebuilding é que, conforme atesta a chamada "Doutrina Capstone" (UN, 2008, p. 1-3) documento da ONU estabelecendo as diretrizes desse tipo de operação de paz - elas passam a ter como atribuição central a coordenação de processos de statebuilding em sociedades devastadas por conflitos. Ora, uma vez que as ditas "raízes estruturais" dos conflitos intraestatais violentos são apontadas como resultantes da incapacidade institucional dos assim chamados "Estados falidos", a reconstrução das capacidades institucionais de governança aparece como solução ideal para promover a "paz sustentável" almejada pelas operações de paz (RICHMOND, 2010, p. 22). Tal reconstrução tem um modelo definido: a promoção de democracias liberais orientadas para o livre mercado de acordo com os princípios da "paz liberal"8, modelo ideológico dominante no "consenso sobre peacebuilding" estabelecido pelos atores centrais da comunidade internacional no contexto pós-Guerra Fria (PARIS, 2004, p. 19; RICHMOND, 2010, p. 22).

Dada essa contextualização geral acerca das operações de peacebuilding contemporâneas, abre-se espaço para a sua análise crítica a partir de uma ênfase em sua dimensão racializada. Um elemento importante nesse sentido é o apontamento de que essas operações são enviadas exclusivamente para países pós-coloniais localizados na "periferia" global, geralmente com composição demográfica majoritariamente não-branca. Nesse sentido, autores como Anievas, Manchanda e Shilliam (2015, p. 10), Branwen Jones (2015, p. 72-73), Daniel Lambach e Tobias Debiel (2010, p. 163), Jonathan Hill (2005, p. 148) convergem ao indicar que o conceito de "Estado falido" -

\footnotetext{
8 A "paz liberal" é composta pela fusão dos argumentos próprios das teorias liberais de "paz democrática" e "paz pelo comércio", grosso modo, que países com regimes democráticos aos moldes republicanos e inseridos nos fluxos do livre mercado mundial tendem a não entrar em guerras entre si. Para uma exposição mais detalhada desse argumento, incluindo as suas origens reflexivas no lluminismo, algumas reformulações contemporâneas e maiores detalhes acerca de sua disseminação pelas operações de paz, sugere-se a leitura de (GUERRA; BLANCO, 2017, p. 262-263).
}

eixo central da narrativa legitimadora das operações de peacebuilding contemporâneas e dos processos de statebuilding inerentes a elas - possui uma carga fortemente ahistórica, pejorativa e racista.

Como lembra Ramon Blanco (2014, p. 294295), a narrativa ortodoxa acerca dos "Estados falidos" os caracteriza dessa forma por serem considerados como incapazes de exercer as tarefas consideradas basilares a um Estado funcional, notadamente o monopólio legítimo sobre o uso da violência, o estrito controle territorial no interior de suas fronteiras e a provisão de bem-estar, segurança e da garantia da lei e da ordem aos seus cidadãos. Frente a essa categorização, autores como Branwen Jones (2015, p. 73) e Jonathan Hill (2005, p. 148) apontam que o modelo de estatalidade considerado "bem-sucedido" e universalmente "ideal" é tipicamente o Estado-Nação moderno europeu.

Assim, os muitos Estados e sociedades periféricos que não se adequam a esse modelo são considerados um "Outro" depravado e aberrante do Self estatal ocidental (HILL, 2005, p. 139-140). Logo, os Estados ditos "falidos" passam a ser apontados pelas narrativas ortodoxas como redutos de uma dupla ameaça: às suas próprias populações, devido à incapacidade de prover-lhes segurança e bem-estar, e aos seus vizinhos e à comunidade internacional de maneira geral, uma vez que são caracterizados como "patológicos", "perigosos", possíveis redutos de criminalidade, células terroristas, redes de narcotraficantes, fluxos de mercado ilegal, dentre outras atividades à margem da legalidade internacional e que postulam eventuais riscos à segurança internacional de maneira geral (LAMBACH; DEBIEL, 2010, p. 163).

Outro elemento crítico apontado pelos autores é que esse tipo de concepção é extremamente ahistórico, desconsiderando de seu escopo analítico o papel estruturante do colonialismo e do imperialismo nas debilidades políticas, sociais e econômicas que conduzem à chamada "falência" dos Estados (HILL, 2005, p. 148; JONES, 


\section{NEIBA}

2015, p. 64). Nas palavras de Jones (2015, p. 65, tradução nossa), a lógica inerente a esse tipo de categorização dos Estados está "irremediavelmente enraizada em uma imaginação racializada e imperial"9 , gerando análises que "tomam uma noção ahistórica e eurocêntrica do Estado como ponto de partida e caracteristicamente focam em processos e condições no interior do Estado, que são examinadas como se isoladas de sua formação histórica e de suas relações globais"10 (JONES, p. 64, tradução nossa).

Uma das consequências desse tipo de abordagem, ainda levando em consideração a carga racista subjacente a ela, é que decorre na marginalização e desconsideração de alternativas locais aos modelos de governança econômica e comunidade política (HILL, 2005, p. 151). De fato, como lembra Vivienne Jabri (2010, p. 49), os discursos relacionados à "falência" dos Estados tendem a indicar as populações desses países estritamente como vítimas passivas, carecendo de intervenções externas por atores "mais desenvolvidos" para serem "salvas" de seus contextos sociais. Tal apontamento é especialmente grave se levarmos em consideração, como fazem M. Ann Brown, VolkerBoege, Kevin Clements e Anna Nolan (2010, p. 102), que as formações políticas e sociais em países pós-coloniais são geralmente complexas, envolvendo uma série de redes não-estatais de autoridade, governança e intercâmbios com importante dimensionalidade no aspecto cotidiano da vida das populações locais.

Outra consequência crítica, ressaltada por Michael Pugh (2004, p. 41) e lan Taylor (2010, p. 169-170), é que os modelos de governança política e econômica liberal disseminados pelas operações de peacebuilding contemporâneas e seus processos de statebuilding beneficiam fundamentalmente às elites transnacionais

\footnotetext{
9 "[...] irredeemably rooted in an imperial and racialised imagination".

10 "[...] take an ahistorical and eurocentric notion of the state as a point of departure and characteristically focus on processes and conditions within the state which are examined in isolation from their historical formation and global relations".
}

responsáveis direta ou indiretamente pelo financiamento e delineamento dessas operações, decorrendo em novas formas de assegurar o controle sobre a superexploração do trabalho (majoritariamente negro e genericamente nãobranco) e apropriação dos recursos naturais dos países periféricos e de suas populações. Taylor (2010, p. 170) ressalta a manutenção no poder de elites locais relacionadas às elites transnacionais (brancas) como resultado do modelo de democracia representativa procedimental proposto pelas operações de paz, enquanto Pugh (2004, p. 40-41) ressalta o papel dessas operações na "estabilização" de áreas lucrativas - pela mão de obra e/ou pela abundância de recursos - às forças dominantes na economia mundial.

Nesse sentido, Branwen Jones (2015, p. 7274) traça uma crítica em especial à proximidade verificada entre as operações de peacebuilding/processos de statebuilding e as teorias de desenvolvimento/modernização. Na perspectiva do autor, semelhante à apontada por Stuart Hall (2017, p. 69-70) e Charles Mills (2015, p. 206), os discursos racistas e racializados baseados em fatores biológicos ou civilizacionais foram "sanitarizados" para os discursos de desenvolvimento e modernização, que apesar de se apresentarem como "race-free", reproduzem a mesma lógica colonialista e racista de hierarquização das sociedades, atribuindo posições superiores aos países "desenvolvidos" brancos e inferiores aos "subdesenvolvidos" não-brancos. Ao invés da categorização da "humanidade" em si, classifica-se a forma institucional dos Estados, legitimando as mesmas práticas de intervenção externa para "instruir" as sociedades periféricas no caminho da modernidade e do desenvolvimento (JONES, 2015, p. 72). Avaliando dinâmicas semelhantes, Roland Paris (2002, p. 639-641) chegou a argumentar que as operações de peacebuilding liberal podem ser analisadas como "missões civilizatórias" contemporâneas ${ }^{11}$.

\footnotetext{
11 Para uma análise da Missão das Nações Unidas para a Estabilização do Haiti (MINUSTAH) sob essa perspectiva, ver (GUERRA; BLANCO, 2017).
} 


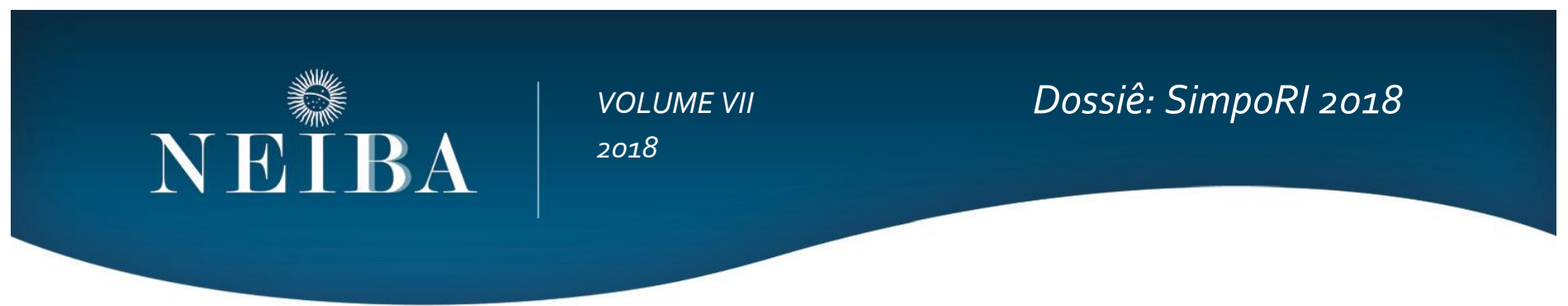

Há ainda o apontamento das operações de paz como instrumentos de vigilância e controle sobre as massas populacionais não-brancas do planeta. Ramon Blanco (2017, p. 96-99) dá um primeiro passo nesse caminho, analisando as operações de peacebuilding como ferramentas de "normalização" e "disciplinarização" dos Estados periféricos e suas populações. Mark Duffield (2016, p. 149) acrescenta a isso a perspectiva de que as operações de paz decorrem em processos de "redescobrimento", remapeamento, categorização e classificação biométrica e, em última instância, de governo de atores do Norte Global sobre populações em cenários pós-conflito no Sul. Michael Pugh (2004, p. 41) soma a essas perspectivas uma consideração acerca do uso da força e da violência pelas tropas militares das operações de paz para conter manifestações, revoltas e revoluções das populações locais de países "indisciplinados", fator potencializado e otimizado pelo uso de novas tecnologias digitais de gerenciamento remoto (DUFFIELD, 2016, p. 149).

Levando esses aspectos em consideração, aqui argumentamos que esses processos analisados por Blanco (2017) e Duffield (2016) e Pugh (2004) se inserem na tendência identificada por AchilleMbembe (2017, p. 22-23) de uso da tecnologia para registrar, protocolar, monitorar e disciplinar corpos, com especial incidência sobre os corpos negros e não-brancos. Essa tendência de categorizar, sistematizar e monitorar a "raça" gerando formas securitizadas de contenção e imobilidade dos corpos nãobrancos de acordo com os "riscos" que supostamente representam para as comunidades brancas (MBEMBE, 2017, p. 35), portanto, pode ser verificada no modus operandi das operações de paz.

Em suma, nosso argumento é que as operações de peacebuilding contemporâneas e os processos de statebuildingintrínsecos a elas estão diretamente atravessados pela "linha global de cor". Tratam-se de instrumentos de ingerência externa que promovem o controle sobre os corpos, o trabalho e os recursos de povos não-brancos em países devastados por conflitos na periferia global. Decorrem, assim, na despossessão do direito fundamental dessas populações de autodeterminação e controle sobre o direcionamento de seus modelos de organização política e econômica, que passam a ser delimitados por agências e atores do Norte Global, de modo a contribuir para a manutenção de uma supremacia branca global, no sentido apresentado por Mills (1997). Em nossa avaliação, o Haiti é um caso exemplar desse tipo de instrumentalização das operações de paz.

\section{Raça e racismo na MINUSTAH: breve estudo da situação do Haiti}

\section{Breve contextualização do histórico de intervenções externas no Haiti}

Em nossa visão, o caso do Haiti é paradigmático para pensar as interconexões entre raça, racismo e relações internacionais, bem como o papel exercido pelas operações de paz nessa trama. De um lado, o Ayti ${ }^{22}$ foi um dos territórios nos quais Colombo desembarcou em sua primeira vinda às Américas, e o primeiro a ser militarmente ocupado pelas tropas espanholas, estando,portanto, no epicentro inaugural da modernidade (e colonialidade) (MATIJASCIC, 2010). Uma das consequências desse processo foi o total genocídio das populações nativas do país, substituídas por quantidades massivas de escravos africanos para a exploração das minas de ouro e trabalho nos canaviais (BÉNOT, 2004, p. 49).

De outro, o país foi o primeiro da América Latina e do Caribe a conduzir um processo revolucionário de independência, a Revolução Haitiana de 1804, primeira do mundo totalmente protagonizada por negros, trazendo como pauta e concretizando como resultado a abolição da escravatura no Haiti (JAMES, 2003, p. 340). Na avaliação de Toni Pressley-Sanon (2014, p. 121), a independência haitiana

\footnotetext{
12 No idioma dos nativos arawak, o termo quer dizer "terra das altas montanhas" (MATIJASCIC, 2010, não paginado).
} 


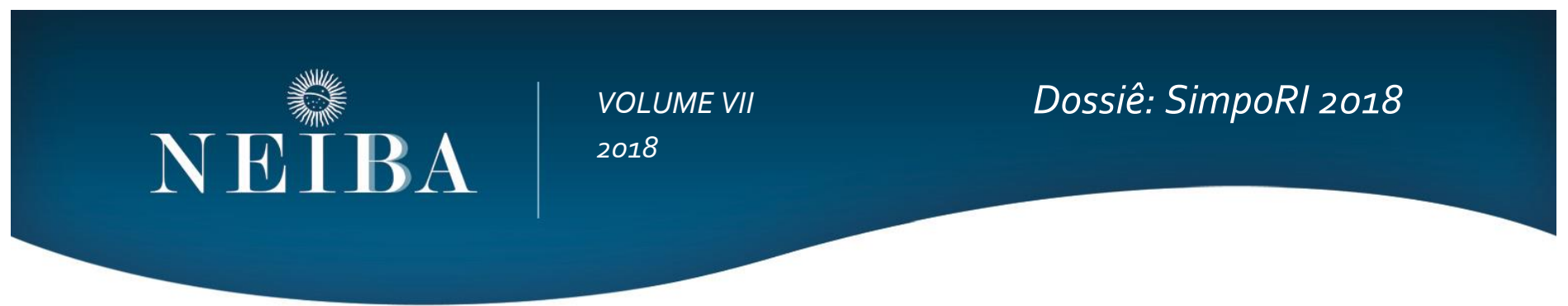

representou um abalo direto a dois dos pilares centrais que estruturavam o imperialismo europeu e o expansionismo estadunidense naquela época: o racismo e o colonialismo.

Nesse sentido, FranckSeguy (2015, p. 259) e Pressley-Sanon (2014, p. 121), respectivamente autor e autora haitianos, convergem ao apontar a resposta racista das potências imperialistas de supremacia branca ao "risco" representado pelo processo revolucionário haitiano de estabelecimento de uma "República Negra": não aceitaram a incorporação de ideais libertários orginalmente europeus por sujeitos negros, não reconheceram a independência do país, isolaram-no das relações com a comunidade internacional, estabeleceram sanções e embargos econômicos e, quando enfim reconheceram a independência do Estado haitiano, cobraram multas milionárias por isso. Na avaliação de BeverleyMullings, Marion Werner e Linda Peake (2010, p. 286), o conjunto de isolamento, embargos e colonialismo financeiro via dívida externa compõem as bases estruturais da inviabilidade de um processo de desenvolvimento no Haiti, culminando nos elevados índices de dependência e pobreza vigentes no país desde então.

Para Pressley-Sanon (2014, p. 116), são essas as bases que conduziram às subsequentes crises, levantes, revoltas, golpes e intervenções externas recorrentes na história do Haiti desde a independência. Um exemplo ressaltado pela autora é a ocupação pelos marines estadunidenses sobre o território haitiano entre 1915-1934, sob discursos legitimadores racistas de que os EUA teriam o dever de '"civilizar' os habitantes do país, em quem pensavam como seus tutelados, crianças atrasadas carentes de orientação paternalista"13 (PRESSLEY-SANON, 2014, p. 117, tradução nossa). O resultado dessa ação paternalista supostamente enviesada para a salvação moral da população haitiana foi a redação de uma nova Constituição para o país, sem participação popular, revogando a proibição anterior à posse de terras por estrangeiros; o reestabelecimento do sistema de corveia de servidão nos campos; o massacre de milhares de campesinos que tentaram resistir a esse processo e a apropriação estadunidense do tesouro e do sistema bancário haitianos (ibidem, p. 126).

Poucas décadas após a retirada das tropas estadunidenses do território haitiano, o país foi dominado por um regime ditatorial de trinta anos de duração, fortemente apoiado pelos EUA, França e Canadá (MULLINGS; WERNER; PEAKE, 2010, p. 287). Entre meados da década de 1980 e início da de 1990, com o fim do regime militar, foi a vez das ingerências externas via proposição de ajustes estruturais pelo Fundo Monetário Internacional (FMI), tendo como resultado a deterioração dos índices de autossuficiência alimentar - de níveis quase autossustentáveis de produção de arroz, o Haiti passou a ser o quarto maior importador mundial do arroz estadunidense , a superexploração de mão-de-obra na indústria têxtil, majoritariamente proveniente de antigos campesinos desapropriados devido ao esvaziamento da produção agrícola nacional, e uma crise social e econômica generalizada no país (ibidem).

Em 1994, houve nova intervenção militar estadunidense para conter os levantes sociais contra essa situação no Haiti (PRESSLEY-SANON, 2014, p. 118). À ocupação direta estadunidense, seguiu-se uma sucessão de seis operações de paz da ONU. Não obstante, a presença onusiana no país não foi suficiente para conter o reescalonamento de conflitos e a ação violenta de grupos armados paramilitares e não-estatais, culminando na deposição do então presidente Jean-Bertrand Aristide em março de 2004. A resposta da comunidade internacional a esse cenário foi o estabelecimento e envio da Missão das Nações Unidas para a Estabilização do Haiti (MINSUTAH), primeira operação de peacebuilding mandada ao país,

13 "[...] 'civilizing' the country's inhabitants whom they thought of as their wards; recalcitrant children in need of paternalistic guidance". 


\section{NEIBA}

inicialmente para um mandato provisório que se estendeu para quase quinze anos de ocupação ${ }^{14}$

\section{Raça e racismo na MINUSTAH}

Enviada ao Haiti em 1 de junho de 2004, a Missão das Nações Unidas para a Estabilização do Haiti (MINUSTAH) tinha em seu mandato original (UNSC, RES 1542/2004) três diretrizes principais: (1) manutenção da segurança, incluindo não só o envio de forças militares e policiais sob o comando da ONU para o país, mas também o desarmamento de ex-combatentes e o treinamento e capacitação da Polícia Nacional Haitiana (PNH); (2) reestabelecimento do processo político, através da promoção da governança democrática, programas de capacitação institucional e organização de eleições; e (3) garantia dos direitos humanos fundamentais, eixo que atraiu uma profusão de agências internacionais, tanto governamentais quanto não-governamentais, para o processo de "estabilização" do Haiti(GUERRA; BLANCO, 2017, p. 266).

Como indica Reginald Dumas (2011, p. 126), a narrativa e lógica subjacentes ao envio da MINUSTAH tem na raça e no racismo o seu componente central, perspectiva corroborada por Pressley-Sanon (2014, p. 130-131), que novamente identifica narrativas de cunho racista e paternalista, enfatizando a "infantilidade" da sociedade haitiana e a sua carência por orientação externa, como parte da legitimação ideológica da Missão. De fato, manifestações do racismo também se verificam nas ações iniciais dos efetivos militares da operação, voltadas para a invasão e controle de bairros periféricos haitianos, como Cité Soleil e

\footnotetext{
14 Para uma contextualização mais detalhada das Missões das Nações Unidas no Haiti predecessoras à MINUSTAH, bem como do escalonamento de conflitos violentos que levou à sua ativação, ver (GUERRA; BLANCO, 2017, p. 265-266)
}

Bel Air, duas maiores "favelas" do país (SEITENFUS, 2016, p. 196-200).

Nesse sentido, Pressley-Sanon (2014, p. 139-141) denuncia que não houve um esforço de distinção entre grupos efetivamente criminosos e movimentos populares armados de contestação ao governo e a Missão, que em um processo de pacificação regular deveriam ter sido incluídos como atores legítimos nas negociações. Como resultado, entre as dezenas de mortes provocadas pelas incursões militares da MINUSTAH nas favelas haitianas, estavam líderes de movimentos de contestação armada com forte respaldo e legitimidade popular (ibidem, p. 140). KeirForgie (2014, p. 62); Mullings, Werner e Peake (2010, p. 296); Pressley-Sanon (2014, p. 139-141); Seguy (2014b, p. 9799); Seitenfus (2016, p. 2000) e a Rede Social de Justiça e Direitos Humanos (2008, p. 217) convergem ao apontar a instrumentalização do aparato militar da MINUSTAH para reprimir a atuação de grupos rebeldes legítimos e manifestações de movimentos sociais, por vezes decorrendo na denúncia de fatalidades e mesmo execuções extrajudiciais.

Além da violência direta contra a população negra periférica do Haiti, a atuação da MINUSTAH decorreu também em outra dimensionalidade do racismo, referente ao modelamento das instituições e práticas políticas e econômicas do país pelas organizações internacionais envolvidas com a Missão, marginalizando a participação da população local (SEGUY, 2015, p. 523). A partir da análise de documentos, relatórios e recomendações elaborados pelas principais agências internacionais envolvidas com a "estabilização" do Haiti - entre elas o Programa das Nações Unidas para o Desenvolvimento (PNUD), o Banco Mundial e o Fundo Monetário Internacional (FMI) - FranckSeguy (2014b, p. 98-100) e Lucas Guerra e Ramon Blanco (2017, p. 267-271) demonstram que as diretrizes da comunidade internacional para o país refletem os princípios de democratização liberal e tentativa de inserção indiscriminada no livre-mercado internacional próprios da "paz liberal", 


\section{NEIBA}

ignorando as particularidades locais haitianas e os impactos socioeconômicos desse tipo de modelo sobre a população.

Entre os impacto socioeconômicos negativos, os autores incluem a superexploração da mão de obra negra haitiana com salários baixíssimos em benefício à indústria têxtil para exportação, fator que tem contribuída para um (baixo) acréscimo no crescimento econômico do país em termos de PIB, embora em detrimento do aumento dos índices de desigualdade social no interior do país (GUERRA; BLANCO, 2017, p. 269-270; SEGUY, 2014b, p. 98100). De fato, esse tipo de controle externo sobre as diretrizes políticas e econômicas do país não decorre somente em uma despossessão do direito à autodeterminação da população haitiana, mas por vezes chega a violar o próprio direito à soberania territorial. Nesse sentido, Seguy (2014a, p. 91-94) denuncia que com a aplicação das diretrizes econômicas propostas sob o âmbito da MINUTSAH, não só a população campesina foi expropriada de suas terras para a instalação de empresas multinacionais, como as próprias autoridades locais de uma das zonas francas do país foram proibidas de ingressas no território dessas empresas.

Reforça-se assim o viés analítico das operações de paz como atravessadas por uma lógica inerentemente racista, de apropriação dos recursos naturais e territórios de regiões da periferia global, superexploração de sua massiva mão-de-obra não-branca e repressão violenta daqueles que contestam o estabelecimento dessa ordem (SEGUY, 2014b, p. 97). Assim, nas palavras do autor, verificase que "o racismo se encontra na gênese ontoepistemológica das políticas em pauta no Haiti" (SEGUY, 2015, p. 523-524). As práticas de fundo racializado e racista da MINUSTAH se intensificaram ainda mais com um ponto de inflexão na atuação da Missão: o terremoto que afligiu a capital Porto Príncipe em 12 de janeiro de 2010. destruição infraestrutural massiva, o terremoto imediatamente instaurou um caos humanitário na já precária situação do Haiti (SEITENFUS, 2016, p. 256). Ao contrário do que seria de se esperar em uma situação como essa, no entanto, a resposta imediata da comunidade internacional não veio na forma de ajuda humanitária, mas de reforço de medidas de segurança e contenção da população no interior das fronteiras do país (MULLINGS; WERNER; PEAKE, 2010, p. 283-284, tradução nossa). No relato das autoras:

Nos dias e semanas seguintes ao terremoto, a contenção como estratégia familiar de controle se tornou a preocupação primária dos Estados poderosos como os Estados Unidos. $O$ exército estadunidense juntou-se às forças da MINUSTAH. Uma das funções primordiais do exército dos EUA era assegurar que os cidadãos haitianos permanecessem na ilha, minimizando a possibilidade de os desalojados chegarem à costa dos Estados Unidos. Cerca de 72 horas após o terremoto, uma grande esquadrilha das Forças Aéreas estadunidenses chegou à costa de Porto Príncipe sem os muito necessitados suprimentos de comida e água [...]. Em vez disso, enquanto os suprimentos chegavam de outros lugares, a esquadrilha de aeronaves serviu como base para a campanha do exército dos EUA de dissuasão de refugiados. Ao invés de providenciar ajuda, um avião de carga fazia voos diários de cinco horas de duração transmitindo mensagens de áudio em Creole e distribuindo panfletos por toda a costa alertando os

Com um total de 300 mil mortos, cerca de mais 300 mil feridos, e 1,3 milhão desabrigados e uma 


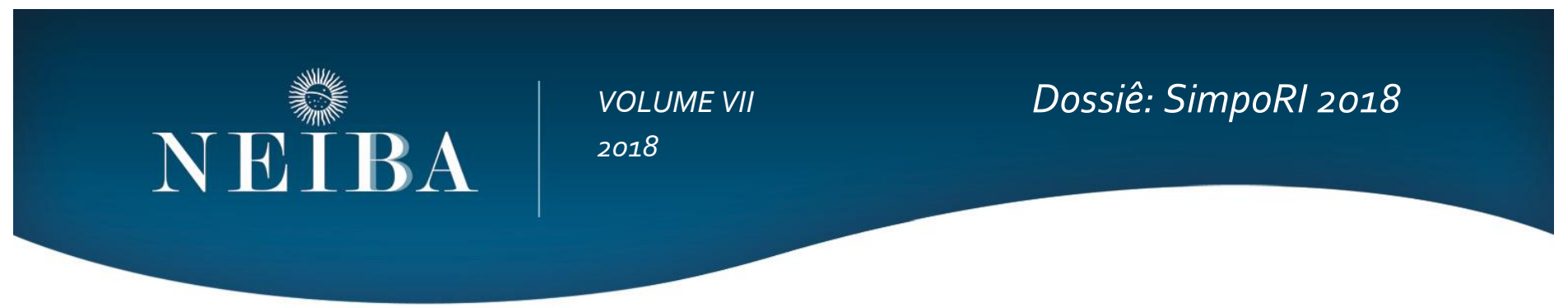

haitianos para não buscarem refúgio pelo mar. $^{15}$

Somado a isso, houve a profusão midiática - e por vezes entre os próprios governos e agências humanitárias - de narrativas apontando o povo haitiano como irracional, violento, perigoso e propenso ao crime (MULLINGS; WERNER; PEAKE, 2010, p. 283). Assim, as reações da comunidade internacional representaram o que as autoras identificam como uma prática recorrente na lida com problemas sociais e crises humanitárias envolvendo populações negras: a criminalização como resposta automática (ibidem, p. 285). Desse modo, a garantia da segurança militarizada no país, alimentada por discursos incitando o medo das populações negras locais, passou a ser apontada como pré-requisito para a prestação de auxílio humanitário, mesmo mediante à situação emergencial do país (ibidem, p. 283).

Além dessa manifestação de racismo com requintes de crueldade, outro aspecto problemático foi a forma de organização das respostas humanitárias à crise no Haiti. Toni Pressley-Sanon (2014, p. 133) e FranckSeguy (2015, p. 523-525) apresentam fortes críticas ao fato de que tanto a população, quanto o próprio governo haitiano, foram amplamente marginalizados dos processos decisórios acerca da alocação de recursos financeiros para fins humanitários. Ambos apontam que as reuniões envolvendo essas temáticas

\footnotetext{
15 In the days and weeks following the earthquake, containment as a familiar strategy of rule became the primary concern of powerful states like the United States. The MINUSTAH forces were joined by the U.S. military. One of the early functions of the U.S. military was to ensure that Haitian citizens remained on the island, minimizing the possibility of the displaced reaching the shores of the United States. Within 72 hours of the earthquake, a large U.S. aircraft carrier arrived off the coast of Port-au-Prince without the much needed supply of food and water [...]. Instead, while supplies were trickling in from elsewhere, the aircraft carrier served as the base for the U.S. military's campaign of refugee deterrence. Rather than provide aid, a cargo plane made daily five-hour long sorties transmitting Creole audio messages and distributing leaflets up and down the coastline warning Haitians not to seek refuge via the sea.
}

se deram fora do Haiti (principalmente em São Domingo, Montreal e Nova York), sendo majoritariamente lideradas por ministros estrangeiros e funcionários de instituições financeiras internacionais, e não pelas autoridades do país. Não por um acaso, como lembra Ricardo Seitenfus (2016, p. 255), a liderança do processo de reconstrução do Haiti ficou concentrada justamente no que o autor chama de Tridente Imperial: França, EUA e Canadá, países historicamente responsáveis pelo colonialismo, neocolonialismo e múltiplas ingerências externas nos assuntos do país.

Assim, a reação da comunidade internacional em suas formulações da reconstrução do país reproduzem, mais uma vez, discursos paternalistas racistas que infantilizam a sociedade haitiana, bem como narrativas pejorativas que apontam as suas autoridades governamentais como naturalmente "corruptas" (MULLINGS; WERNER; PEAKE, 2010, p. 293; PRESSLEYSANON, 2014, p. 133). Tais tipos de narrativa justificaram a alocação de recursos financeiros para a ajuda humanitária majoritariamente nas mãos de organizações nãogovernamentais instaladas no país (SEGUY, 2015, p. 523). Desse modo, Mullings, Werner e Peake (2010, p. 288-289) demonstram que a cada um dólar destinado pelo governo dos Estados Unidos para a reconstrução do Haiti, apenas 1 centavo ia para o governo haitiano, enquanto que 33 se voltavam para o Exército e 42 eram distribuídos entre as mais de dez mil ONGs atuantes no país.

FranckSeguy (2015, p. 522-532) é extremamente crítico à presença e à forma de atuação dessa quantidade massiva de ONGs em território haitiano. $\mathrm{Na}$ avaliação do autor, além da despossessão do direito do povo de governar a si mesmo ressaltado por Mullings, Werner e Peake (2010, p. 288), essas organizações trazem novas formas de marginalização e mesmo impactos econômicos negativos para o Haiti. Seguy (2015, p. 523) denuncia a ausência de representantes haitianos nas reuniões coordenadas de agências humanitárias governamentais e não-governamentais no país, bem como o fato de que essas 


\section{NEIBA}

reuniões, quando ocorrem em território haitiano, se dão em inglês, idioma inacessível para uma parcela significativa da população. Além disso, ocorrem em prédios e construções cujo luxo é especialmente contrastante com relação à miséria imperante no Haiti, prédios esses aos quais à população tem acesso extremamente restrito (p. 522-523).

Seguy(2015, p. 524) critica ainda formas de racismo presentes na atuação dessas organizações, como o pagamento de altos salários para "meninos estrangeiros de olhos azuis", enquanto que haitianos de pele negra no país ou na diáspora com qualificações semelhantes recebem salários até três vezes menores pelo mesmo tipo de função. Outro aspecto denunciado pelo autor é a especulação imobiliária e aumento de preço de bens e serviços básicos motivado pela presença de milhares de funcionários internacionais com salários altos no país, o que dificulta ainda mais o acesso da população à moradia e à alimentação (SEGUY, 2014b, p. 105). Assim:

De um lado estão as milhares de organizações de ajuda que vêm ao Haiti com a totalidade do orçamento da ajuda internacional nas suas contas bancárias (bilhões no total), onde construíram um poderoso Estado paralelo que presta conta a ninguém mais que seus contribuintes $e$ patrões. Do outro lado, estão os representantes do povo haitiano, oficiais eleitos, representantes de organizações da sociedade civil, empresários, que permanecem pobres e abandonados por essas ONGs que vêm para socorrê-los. E entre os dois? $O$ povo haitiano, pobre, desempregado, desabrigado e abalado por esses esforços de reconstrução que frequentemente se esquecem de lhe prestar qualquer ajuda (SEGUY, 2015, p. 523).
Finalmente, gostaríamos de evitar uma abordagem também racista de apontamento da população haitiana como mera "vítima" ou receptora passiva dos processos aqui expostos e denunciados. Apesar de as múltiplas formas de racismo e opressão, o povo haitiano demonstra formas de resistência e iniciativas para tomar de volta a posse sobre o seu direito à autodeterminação. Reginald Dumas (2011, p. 137), por exemplo, aponta os esforços de organizações da sociedade civil e movimentos sociais haitianos em compor plataformas e coalizões para a denúncia das vicissitudes da MINUSTAH em instâncias internacionais, bem como em formular propostas de alternativas aos modelos políticos, sociais e econômicos implementados pela Missão. Toni Pressley-Sanon (2014, p. 132-141), por sua vez, indica formas de resistência na dimensão do dia-a-dia da vida das pessoas, como as redes entrecruzadas de solidariedade entre associações barristas, grupos religiosos e famílias que se organizaram para prover serviços básicos de assistência física e psicológica no imediato pós-terremoto, os cânticos jocosos emitidos pela população quando passam perto de soldados da MINUSTAH, as pichações e grafites nos muros das cidades ou mesmo a presença popular massiva no funeral de Emmanuel DreadWilmer, um dos líderes rebeldes assassinado pelas tropas da MINUSTAH nas incursões militares à Cité Soleil.

\section{Considerações Finais}

No presente artigo, argumentamos que a raça e o racismo são elementos estruturantes das relações internacionais - tanto de sua dimensão disciplinar quanto da política mundial conforme instituída desde a modernidade e que as operações de paz são um exemplo nesse sentido. Assim, na primeira seção enfatizamos que a raça é um "significante escorregadio" slidingsignifier (HALL, 2015), sendo continuamente ressignificada ao longo dos séculos, mas mantendo o caráter inerente de categorização hierárquica da humanidade entre povos brancos (superiores) 


\section{NEIBA}

e não-brancos (inferiores). Na segunda seção, analisamos as formas com que à lógica inerente às operações de paz contemporâneas é atravessada pela "linha de cor global", com especial atenção para o racismo presente em categorias centrais da narrativa internacional para a resolução de conflitos e construção da paz, como os de "Estado falido" e statebuilding.

Finalmente, na terceira seção procuramos dar uma maior materialidade para as considerações teóricas e conceituais apresentadas nas seções anteriores, através de um estudo de caso da Missão das Nações Unidas para a Estabilização do Haiti (MINUSTAH). Em nossa perspectiva, a Missão reproduz uma série de elementos racistas presentes nas abordagens da comunidade internacional ao país desde a sua colonização, e especialmente a partir das retaliações ocidentais à Revolução Haitiana antiescravista e anticolonialista instaurada em 1804 .

Dentre esses elementos, estão uma visão de paternalismo racista da comunidade internacional com relação a uma população haitiana apontada como "infantil", incapaz e carente de orientação externa para se desenvolver, quando não como uma sociedade "corrupta", "irracional" e "pendente à criminalidade". Disso, decorrem processos de despossessão de alguns dos direitos fundamentais do povo haitiano, como o de autodeterminação dos rumos políticos e econômicos do país e, por vezes, da própria soberania territorial. Além disso, o racismo também se manifesta nas soluções militarizadas apresentadas pela Missão para os problemas sociais e levantes populares existentes no país.

Em nossa perspectiva, denunciar esses elementos presentes na operação não significa negar que a sua atuação foi em muitas ocasiões benéfica à população haitiana, evitando a deterioração das já precárias condições do país. Mesmo críticos ferrenhos da MINUSTAH, como Pressley-Sanon (2014, p. 146) e Mullings, Werner e Peake (2010, p. 293-294), reconhecem elementos positivos nas tentativas de pacificação e promoção do desenvolvimento no Haiti. Convergimos com essas autoras, bem como com FranckSeguy (2015, p. 532) e Reginald Dumas (2011, p. 128), no apontamento de que qualquer solução efetiva para o problema da violência, da pobreza e das condições precárias do desenvolvimento no Haiti devem passar pela abertura de espaços centrais para o protagonismo da população do país, garantindo - e não reduzindo - o seu pleno exercício de autogoverno e autodeterminação. 


\section{NEIBA}

VOLUME VII

\section{Dossiê: SimpoRI 2018}

\section{8}

\section{BIBLIOGRAFIA}

Aalberts, T., 2014. Rethinking the Concept of (Sovereign) Equality as a Standard of Civilisation. Millennium: Journal of International Studies, Volume 42, pp. 767-789.

Anievas, A., Manchanda, N. \& Shilliam, R., 2015. Confronting the global colour line: an introduction. In: A. Anievas, N. Manchanda \& R. Shilliam, eds. Race and racism in international relations: confronting the global colour line. New York: Routledge, pp. 1-16.

Bellamy, A., Williams, P. \& Griffin, S. (2010). Understanding Peacekeeping. 2 ed. Cambridge: Policy.

Bénot, Y., 2004. A destruição dos índios da área caribenha. Em: M. Ferro, ed. O Livro Negro do Colonialismo. Rio de Janeiro: Ediouro, pp. 48-59.

Blanco, R., 2014. Del mantenimiento de la paz al proceso de formación del Estado: un esbozo de los esfuerzos de la ONU para la paz internacional. Foro Internacional, 54(2), pp. 266-318.

Blanco, R., 2017. Normalizando anormais na sociedade internacional: operações de paz, Foucault e a Escola Inglesa. Relações Internacionais, Volume 53, pp. 83-107.

Brown, M., Boege, V., Clements, K. \& Nolan, A., 2010. Challenging statebuilding as peacebuilding: working with hybrid political orders to build peace.. Em: O. Richmond, ed. Palgrave Advances in Peacebuilding: Critical Developments and Approaches. Basingstoke: Palgrave Macmillan, pp. 99-115.

Du Bois, W., 1925. Worlds of Color. Foreign Affairs, 333), pp. 423-444.

Duffield, M., 2016. The resilience of the ruins: towards a critique of digital humanitarism. Resilience, 4(3), pp. 147-165.

Dumas, R., 2011. Haiti at the intersections of the world: Tapping the past, facing the future. The Journal of Haitian Studies, 17(2), pp. $124-145$.

Escobar, A. (2007). La invención del Tercer Mundo: Construcción y deconstrucción del desarrollo. Caracas: Fundación Editorial el perro y la rana.

Forgie, K., 2014. US Imperialism and Disaster Capitalism in Haiti. Good intentions: norms and practices of Imperial Humanitarism, Volume 4.

Guerra, L. \& Blanco, R., 2017. A MINUSTAH como uma Missão Civilizatória: Uma Análise Crítica da Política Internacional para a Estabilização do Haiti. Revista de Estudos Internacionais, 8(3), pp. 259-275.

Guerra, L. \& Blanco, R., 2018. A Construção da Paz no Cenário Internacional: do Peacekeeping Tradicional às Críticas ao Peacebuilding Liberal. Carta Internacional, 13(2), pp. 5-30.

Hall, S. (2017). The Fateful Triangle: Race, Ethnicity, Nation. Cambridge: Harvard University Press. 


\section{NEIBA}

Hill, J., 2005. Beyond the Other? A postcolonial critique of the failed state thesis. African Identities, 3(2), pp. 139-154.

Jabri, V., 2010. War, government, politics: a critical response to the hegemony of liberal peace. Em: O. Richmond, ed. Palgrave advances in peacebuilding: critical developments and approaches. Basingstoke: Palgrave Macmillan, pp. 41-57.

Jahn, B., 2007. The Tragedy of Liberal Diplomacy: Democratization, Intervention, Statebuilding (Part II). Journal of Intervention and Statebuilding, 1(2), pp. 211-229.

James, C. (2003). Los jacobinos negros: Toussaint L'Overture y la Revolución de Haiti. Madrid: Turner Publicaciones.

Jones, B. G., 2015. 'Good governance' and 'state failure': the pseudo-science of statemen in our times. Em: A. Anievas, N. Manchanda \& R. Shilliam, eds. Race and racism in international relations: confronting the global colour line. New York: Routledge, pp. 62-80.

Kenkel, K., 2013. Five generations of peace operations: from the "thin blue line" to "painting a country blue". Revista Brasileira de Política Internacional, 56(1), pp. 122-143.

Krishna, S. (2009). Globalization and Postcolonialism: Hegemony and Resistance in the Twenty-First Century. Lanham: Rowman \& Littlefield.

Lambach, D. \& Debiel, T., 2010. State failure and State building. Em: M. CAVELTY \& V. MAUER, eds. The Routledge Handbook of Security Studies. London: Routledge, pp. 159-169.

Matijascic, V. B., 2010. Haiti: uma história de instabilidade política. Anais do XX Encontro Regional de História: História e Liberdade.

Mbembe, A. (2017). Critique of black reason. Durham: Duke University Press.

Mignolo, W. D. (2003). Historias locales/diseños globales: Colonialidad, conocimientos subalternos y pensamiento fronterizo. Madrid: Akal.

Mills, C. (1997). The Racial Contract. London: Cornell University Press.

Mills, C. W., 2015. Unwriting and Unwhitening the World. Em: A. Anievas, N. Manchanda \& R. Shilliam, eds. Race and racism in international relations: confronting the global colour line. New York: Routledge, pp. 202-214.

Mullings, B., Werner, M. \& Peake, L., 2010. Fear and Loathing in Haiti: Race and Politics of Humanitarian Dispossession. ACME: An International E-Journal for Critical Geographies, 9(3), pp. 282-300.

Paris, R. (2004). At War's End: Building Peace After Civil Conflict. Nova York: Cambridge University Press.

Pressley-Sanon, T., 2014. Haitian (Pre)Occupations: Ideological and Discursive Repetitions: $1915-1934$ and 2004 to Present. Caribbean Studies, 42(2), pp. 115-153.

Pugh, M., 2004. Peacekeeping and Critical Theory. International Peacekeeping, 11(1), pp. 39-58. 


\section{NEIBA}

VOLUME VII

Dossiê: SimpoRI 2018

2018

Quijano, A., 2005. Colonialidade do poder, eurocentrismo e América Latina. Em: E. Lander, ed. A colonialidade do saber: eurocentrismo e ciências sociais. Perspectivas latino-americanas. Buenos Aires : CLACSO, pp. 107-130.

Rede Social de Justiça e Direitos Humanos, 2008. Human Rights in Brazil 2008, São Paulo: s.n.

Richmond, O., 2010. A genealogy of peace and conflict theory. Em: O. Richmond, ed. Palgrave Advances in Peacebuilding: Critical Developments and Approaches. Basingstoke: Palgrave Macmillan, pp. 14-38.

Saraiva, J. M., 2018. O apagamento da ideia de Raça e o campo de estudos das Relações Internacionais: colonialidade do saber e as violências epistêmicas. Anais Complementares do $4^{\circ}$ Seminário de Relações Internacionais - ABRI.

Seguy, Franck (2014a). A catástrofe de janeiro de 2010, a "Internacional Comunitária" e a

recolonização do Haiti. Tese (doutorado) - Universidade Estadual de Campinas, Instituto de Filosofia e Ciências Humanas, UNICAMP, Campinas. Disponível em: <http://diversitas.fflch.usp.br/sites/diversitas.fflch.usp.br/files/tese-franck\%2oseguy.pdf>. Acesso em: 26 out. 2018

Seguy, F., 2014b. Para compreender a recolonização do Haiti. Revista Outubro, Volume 22, pp. 79-108.

Seguy, F., 2015. Racismo e desumanização no Haiti. Educere et Educare: Revista de Educação, 10(20), pp. $521-536$.

Seitenfus, R. (2016). Reconstruir Haití: entre la esperanza y el Tridente Imperial. Santo Domingo: Fundação Juan Bosch.

Smith, S., 2000. The discipline of international relations: still an American social science?. British Journal of Politics and International Relations, 2(3), pp. 374-402.

Taylor, I., 2010. Liberal peace, liberal imperialism: a gramscian critique. Em: O. Richmond, ed. Palgrave Advances in Peacebuilding: Critical Developments and Approaches. Basingstoke: Palgrave Macmillan, pp. 154-175.

United Nations (UN), 1992. Secretary-General. An Agenda for Peace: preventive diplomacy, peacekeeping and peace-making, New York: s.n.

United Nations (UN), 2008. Department of Peacekeeping Operations. United Nations Peacekeeping Operations: Principles and Guidelines, New York: s.n.

United Nations Security Council (UNSC), 2004. Resolution 1542/2004. 